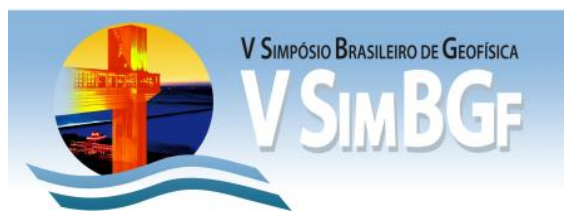

\title{
The pore geometry and saturation effects on the modeling elastic properties of carbonate rocks
}

Irineu de A. Lima Neto*, Roseane M. Misságia, Marco A. R. de Ceia and Nathaly L. Archilha.

Laboratório de Engenharia e Exploração de Petróleo (LENEP) - Universidade Estadual do Norte Fluminense (UENF)

Copyright 2012, SBGf - Sociedade Brasileira de Geofísica

Este texto foi preparado para a apresentação no V Simpósio Brasileiro de Geofísica, Salvador, 27 a 29 de novembro de 2012. Seu conteúdo foi revisado pelo Comite Técnico do V SimBGf, mas não necessariamente representa a opinião da SBGf ou de seus associados. É proibida a reprodução total ou parcial deste material para propósitos comerciais sem prévia autorização da SBGf.

\section{Summary}

Rock Physics studies can collaborate to identify the carbonate's pore system heterogeneities, allowing the prediction of elastic parameters and seismic velocities in time-lapse modeling. This work is based on the effective medium theories and Gassmann's model to characterize and classify porosity according to the pore types. The methodology was applied in the Glorieta-Paddock carbonate reservoir at the Vacuum field, New Mexico, to estimate elastic properties under dry and saturated conditions. The results indicated the greatest potential of Upper Paddock formation to store fluids and increased seismic sensitivity due to the interparticle pore aspect under the influence of microcracks in limestone, reflecting a lower stiffness rock and increasing seismic sensibility for fluid saturation. The Lower Paddock and Glorieta formations consist of dolomite with interparticle pore aspect under influence of spherical pore shapes, showed a reduction in seismic sensitivity due to the increase of rock stiffness. Under the conditions imposed in this study, we verified that the application of the effective medium theories, specially the KT model, proved to be better than Gassmann's model to express seismic velocity anomalies.

\section{Introduction}

Carbonate rocks are generally composed by heterogeneous pore systems. This heterogeneity can be expressed by a combination of pore geometries, correlating the effect of changes in elastic modulus to seismic reservoir monitoring. Anselmetti \& Eberli (1999), Kumar \& Han (2005) and Xu \& Payne (2009) showed that carbonate rocks are featured by three types of porosity: 1 ) rounded or spherical pores - moldic, vuggy or intraframe porosity occurrences; 2) interparticle pores intercrystalline porosity; and 3) microporosity or microcracks - microfractures and channels occurrences.

Experimental studies have been developed for understanding the pore system in carbonate rocks. Ultrasonic studies about the complex nature of carbonate rocks can lead to ambiguous conclusions when interpreting seismic data for reservoir characterization are affected by texture, mineralogy, pore space and pore fluid, for example. Pressure and temperature are indirect factors that also change the elastic modulus. However, the pore shape is the most significant carbonate property affecting the elastic modulus (Gregor et al., 2007). There are several rock physics models for estimate the seismic velocity versus saturation, of which low frequency Gassmann's model (Gassmann, 1951) probably is the most well known (Misagui et al., 2010). Besides effective medium theories have been applied in carbonate case study, there are some models: KT-Kuster-Toksöz (Kuster \& Toksöz, 1974; Berryman, 1980), SC-Self Consistent (Wu, 1966; O'Connell \& Budiansky, 1974; Berryman, 1980, 1995), DEM-Differential Effective Medium (Norris, 1985; Zimmerman, 1984; Berryman, 1992).

In this ultrasonic conditions study, the pore fluid was treated as an elastic inclusion for such brine, oil and gas phase saturation (Mavko et al., 1998; Ruiz \& Dvorkin, 2010). However, an approach of the fluid substitution can be used by combination the effective medium theories for dry conditions (ultrasonic domain) and then applying Gassmann's model for fluid saturation (low-frequency domain) (Xu \& White, 2005; Xu \& Payne, 2007). KT is a generalization for a variety of inclusion shapes with volume concentration in background medium, each set of inclusions must be distributed randomly assumption isotropic effect (Mavko et al., 1998). SC treats grains and pores symmetrically instead of requiring a single background material, grains and pores can be connected or disconnected depending on the porosity range. DEM assumes isolated pores embedded in a host material that remains continuous at all porosities (Ruiz \& Dvorkin, 2010). We applied Gassmann's model and the effective medium theories in case study of Glorieta-Paddock carbonate reservoir at Vacuum field, New Mexico.

\section{Methodology}

We proposed in this study:

- Characterize and classify the geometry of pores.

- Set the multiporous system by effective medium theories, to consider a dual pore system.

- Evaluate effective medium theories for carbonate rocks under fluid saturation conditions by approach ultrasonic domain.

\section{Data set: Glorieta-Paddock carbonate reservoir at Vacuum field, New Mexico}

Vacuum field, discovered in 1929, is mainly composed of Paleozoic sedimentary carbonates and evaporites, complemented by the cumulative production for the Permian dolomites Grayberg and San Andreas 
formations. Also collaborate economically with the two formations subsequent to San Andreas, called Glorieta and Paddock, (Acuna, 2000; Grammer et al., 2004).

Glorieta formation is characterized by naturally fractured dolomitic sandstones with isolated pore zones of lenticular type. Paddock is divided into upper and lower portion. In the Upper Paddock there is a predominance of dolomite with intercrystalline and vuggy porosity. However, at irregular intervals occurs limestone vuggy and moldic porosity, representing the main production area. The Lower Paddock is characterized by highly fractured dolostone. In the Fig. 1, the samples of GlorietaPaddock rocks are characterized, emphasizing the possibility of: 1) sandy dolomite in Glorieta, 2) limestone of excellent porosity and permeability in Upper Paddock, also low porosity and permeability dolostone occurrences, and 3) fractured dolostone in Lower Paddock.

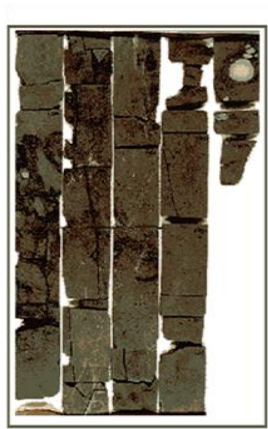

(A)

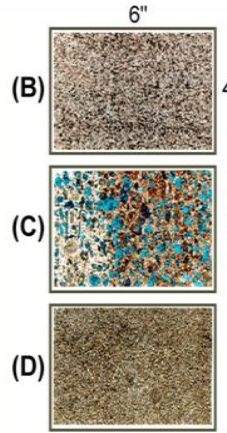

Glorieta

4" Porosity: $5 \%$

Permeability: $0.07 \mathrm{mD}$

Upper Paddock

Porosity: $24.2 \%$

Permeability: $22.7 \mathrm{mD}$

Lower Paddock

Porosity: $3.1 \%$

Permeability: $0.02 \mathrm{mD}$
Figure 1 - Description of Glorieta-Paddock carbonate reservoir (after Acuna, 2000): 1- Glorieta consists of dolomitic sandstones (B); 2- Upper Paddock porous limestone (C); 3- Lower Paddock fractured dolostone ( $A$, $D$ ). We used data from logs and core samples for five wells in the study area.

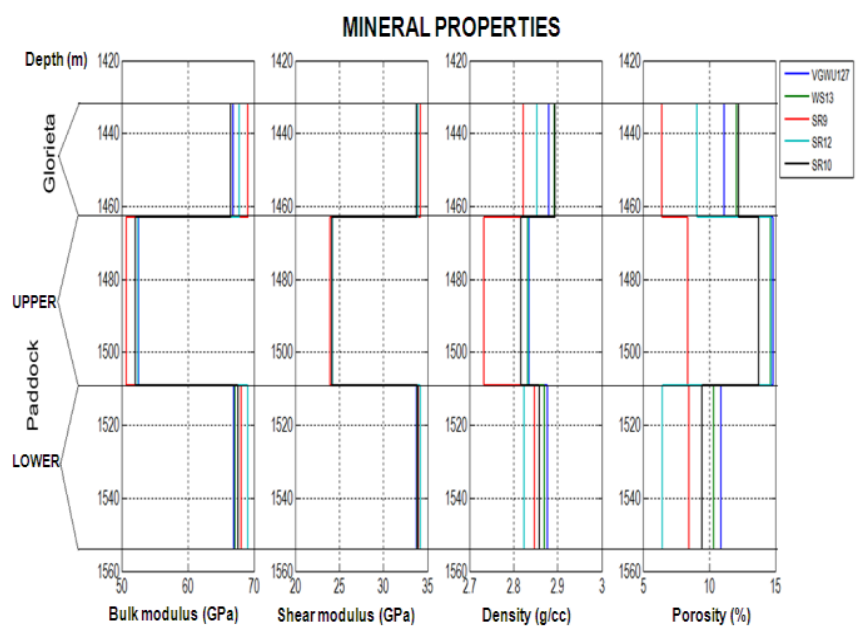

Figure 2 - Mineral properties derived from logs and core samples for five wells in Glorieta-Paddock reservoir (after Acuna, 2000): bulk modulus, shear modulus, density and porosity.

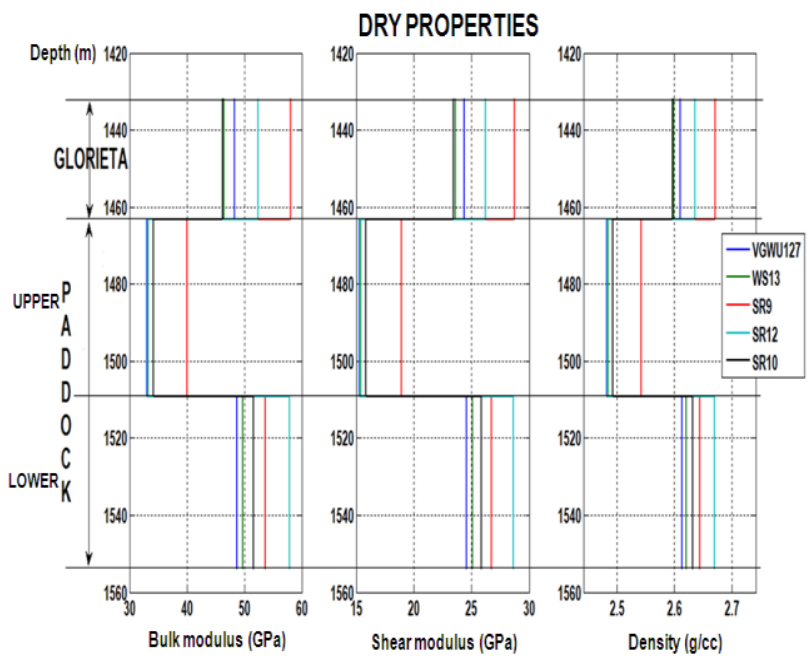

Figure 3 - Dry properties calculated by Nur et al. (1995) theory from logs and core samples for five wells in Glorieta-Paddock reservoir (after Acuna, 2000): bulk modulus, shear modulus and density.

Table 1 - Glorieta-Paddock data set overview after Acuna (2000). Mineral and dry properties derived from logs and core samples of according to Figures 2 and 3.

\begin{tabular}{|c|c|c|c|c|c|c|c|c|}
\hline \multirow[b]{2}{*}{ Formation } & \multirow[b]{2}{*}{ Well } & \multirow[b]{2}{*}{$\begin{array}{c}\text { Porosity } \\
(\%)\end{array}$} & \multicolumn{3}{|c|}{ Mineral } & \multicolumn{3}{|c|}{ Dry } \\
\hline & & & $\begin{array}{c}\text { Bulk } \\
\text { modulus } \\
\text { (GPa) }\end{array}$ & $\begin{array}{c}\text { Shear } \\
\text { modulus } \\
(\mathrm{GPa})\end{array}$ & $\begin{array}{l}\text { Density } \\
\left(\mathrm{g} / \mathrm{cm}^{3}\right)\end{array}$ & $\begin{array}{c}\text { Bulk } \\
\text { modulus } \\
(\mathrm{GPa})\end{array}$ & $\begin{array}{c}\text { Shear } \\
\text { modulus } \\
\text { (GPa) }\end{array}$ & $\begin{array}{l}\text { Density } \\
\left(\mathrm{g} / \mathrm{cm}^{3}\right)\end{array}$ \\
\hline \multirow{5}{*}{ Glorieta } & VGWU127 & 11.14 & 66.87 & 33.80 & 2.88 & 48.25 & 24.38 & 2.61 \\
\hline & WS-13 & 12.08 & 66.52 & 33.78 & 2.89 & 46.43 & 23.58 & 2.60 \\
\hline & SR-9 & 6.41 & 69.14 & 34.22 & 2.82 & 58.06 & 28.74 & 2.67 \\
\hline & SR-12 & 9.07 & 67.77 & 33.91 & 2.85 & 52.40 & 26.22 & 2.64 \\
\hline & SR-10 & 12.20 & 66.46 & 33.76 & 2.89 & 46.19 & 23.46 & 2.60 \\
\hline \multirow{5}{*}{$\begin{array}{c}\text { Upper } \\
\text { Paddock }\end{array}$} & VGWU127 & 14.83 & 52.57 & 24.26 & 2.84 & 33.08 & 15.27 & 2.48 \\
\hline & WS-13 & 14.63 & 52.47 & 24.24 & 2.83 & 33.28 & 15.38 & 2.49 \\
\hline & SR-9 & 8.37 & 50.66 & 23.96 & 2.73 & 40.06 & 18.95 & 2.54 \\
\hline & SR-12 & 14.71 & 52.50 & 24.24 & 2.83 & 33.19 & 15.33 & 2.48 \\
\hline & SR-10 & 13.77 & 52.11 & 24.15 & 2.82 & 34.17 & 15.84 & 2.49 \\
\hline \multirow{5}{*}{$\begin{array}{c}\text { Lower } \\
\text { Paddock }\end{array}$} & VGWU127 & 10.89 & 66.97 & 33.80 & 2.88 & 48.74 & 24.60 & 2.61 \\
\hline & WS-13 & 10.36 & 67.19 & 33.84 & 2.87 & 49.79 & 25.07 & 2.62 \\
\hline & SR-9 & 8.49 & 68.05 & 33.98 & 2.85 & 53.61 & 26.76 & 2.65 \\
\hline & SR-12 & 6.48 & 69.09 & 34.21 & 2.82 & 57.90 & 28.66 & 2.67 \\
\hline & SR-10 & 9.46 & 67.58 & 33.88 & 2.86 & 51.60 & 25.87 & 2.63 \\
\hline
\end{tabular}

We studied the five wells logs average to estimate the elastic and petrophysical reservoir considered for each layer: Glorieta, Upper Paddock and Lower Paddock. It was observed that the Upper Paddock has a great potential to fluid accumulation. Thus, Fig. 2 shows the media logs for the mineral composition, and the dry rock conditions in the Fig. 3, that was used to apply the rock physics models. The data set overview has been listed in Tab. 1, where a small difference between well logs is observed in each formation. It should be noted the predominance of carbonate rock limestone in Upper Paddock, featuring the main reservoir zone to be studied. 


\section{Characterization and classification of the geometry of pores}

The diagenetic texture of carbonates is related to processes which lead to the different kinds of pore carbonate rocks (Moore, 1989). Usually, the texture carbonate is classified as the propositions of Folk (1959) and Dunham (1962). For applying of the effective media models according to the study methodology proposed, it is necessary to predict the pore geometry of carbonate rocks. Thus, we performed a correlation of the textural observations with the dry bulk modulus comportment by an idealized pore type classification (Kumar \& Han, 2005; Xu \& Payne, 2009; Wang \& Sun, 2010) for the input data analysis of Paddock and Glorieta formations (Fig. 4). Basically, the authors suggest three classes for the pore volume in clean carbonates, with the possibility of variation between different types: 1) rounded or spherical pores - representing the occurrence of moldic, vugs and intraparticle porosity; 2) interparticle porosity intercristaline; and 3) fractured pores (cracks) or microporosity - occurrence of microfractures or microcracks and channels in low porosity carbonates. The interparticle porosity is assumed as reference in carbonate rocks and can be influenced by rounded pores making the rock more rigidity, or by fracturing influence generating microporosity and leading the rock less rigidity. Tab. 2 shows the pore shape evaluation in Glorieta-Paddock reservoir. The heterogeneous medium in the pores are expressed by the statistical distribution of aspect ratio.

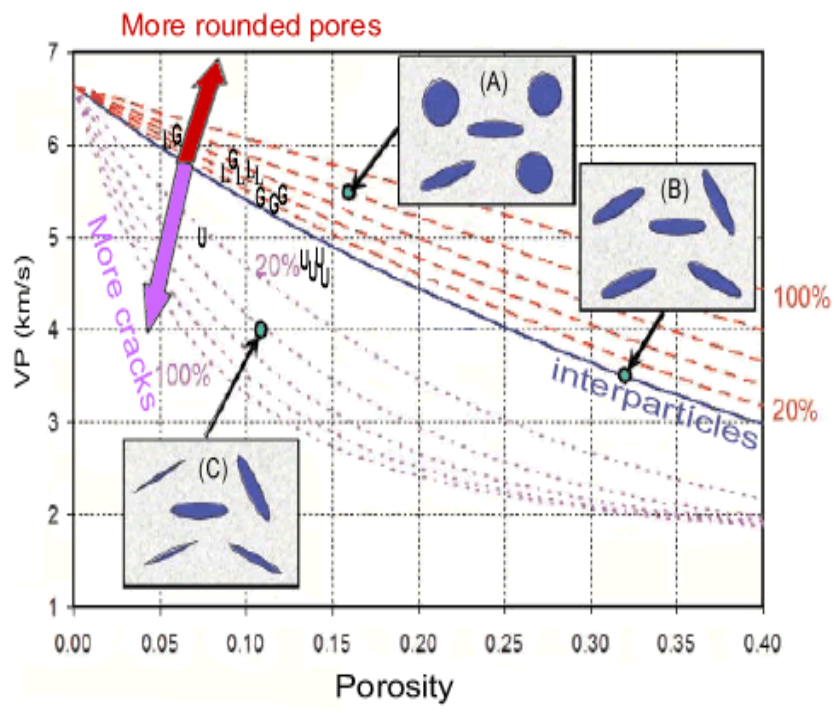

Figure 4 - Evaluation of the pore type in carbonates: the red arrow indicates increase of rounded pores, and the purple arrow indicates the increase of microfractures and microporosity. The blue line is the reference to interparticle pores (after Han \& Kumar, 2005; Xu \& Payne, 2009). The points marked by $G, U$ and $L$ were calculated for the dry rock properties in Glorieta, Upper Paddock and Lower Paddock, respectively. The idealization of pore type: (A) $80 \%$ rounded, (B) interparticle reference line, and (C) $40 \%$ microfractures.
Table 2 - Influence of pore shape for the inclusion distributions of well data in reference to interparticle line: Glorieta formation - rounded, Upper Paddock microcracks and Lower Paddock - rounded.

\begin{tabular}{|c|c|c|c|}
\hline Well & \multicolumn{2}{|c|}{ Formation } & $\begin{array}{c}\text { Geometric } \\
\text { influence of } \\
\text { the porosity } \\
\text { (Interparticles } \\
\text { baseline) } \\
\text { R- Rounded } \\
\text { C-Cracks }\end{array}$ \\
\hline \multirow{3}{*}{ VGWU127 } & \multicolumn{2}{|c|}{ Glorieta } & $20 \%-R$ \\
\hline & \multirow{2}{*}{ Paddock } & Upper & $10 \%-C$ \\
\hline & & Lower & $40 \%-R$ \\
\hline \multirow{3}{*}{ WS-13 } & \multicolumn{2}{|c|}{ Glorieta } & $20 \%-\mathrm{R}$ \\
\hline & \multirow{2}{*}{ Paddock } & Upper & $10 \%-C$ \\
\hline & & Lower & $40 \%-R$ \\
\hline \multirow{3}{*}{ SR-9 } & \multicolumn{2}{|c|}{ Glorieta } & $40 \%-R$ \\
\hline & \multirow{2}{*}{ Paddock } & Upper & $20 \%-C$ \\
\hline & & Lower & $20 \%-\mathrm{R}$ \\
\hline \multirow{3}{*}{ SR-12 } & \multicolumn{2}{|c|}{ Glorieta } & $40 \%-R$ \\
\hline & \multirow{2}{*}{ Paddock } & Upper & $10 \%-C$ \\
\hline & & Lower & $20 \%-R$ \\
\hline \multirow{3}{*}{ SR-10 } & \multicolumn{2}{|c|}{ Glorieta } & $20 \%-R$ \\
\hline & \multirow{2}{*}{ Paddock } & Upper & $10 \%-C$ \\
\hline & & Lower & $20 \%-R$ \\
\hline
\end{tabular}

\section{Sensibility of elastic effective medium models}

We present the results of applying the effective elastic media (KT, SC and DEM) and Gassmann's model in the data set of the Glorieta-Paddock reservoir, in order to verify the model that best expresses the anomalies observed in seismic data by Acuna (2000), especially in Upper Paddock areas saturated with oil and gas.

Evaluating the Glorieta and Paddock formations, the bulk modulus changes are not significantly in Glorieta and Lower Paddock for dry and saturated conditions. Therefore, the Upper Paddock represents an area with greater permeability and porosity that assure better reservoir conditions by the occurrence of microporosity (Fig. 5). It was not possible to observe significant changes in the bulk modulus of phase adopting the saturation Gassmann's model, but the effective elastic medium models were able to reflect changes in bulk modulus in the order of sensitivity models: DEM $<\mathrm{SC}<\mathrm{KT}$, where $\mathrm{SC}$ had a very similar behavior to $\mathrm{KT}$.

We can check in the comparison of effective elastic medium models that can be overestimate or underestimate on bulk modulus behavior for phase saturation taking into account the dry line. After, the KT model was chosen for differentiation of the fluid saturation and lithology by the great expression of sensitivity. 

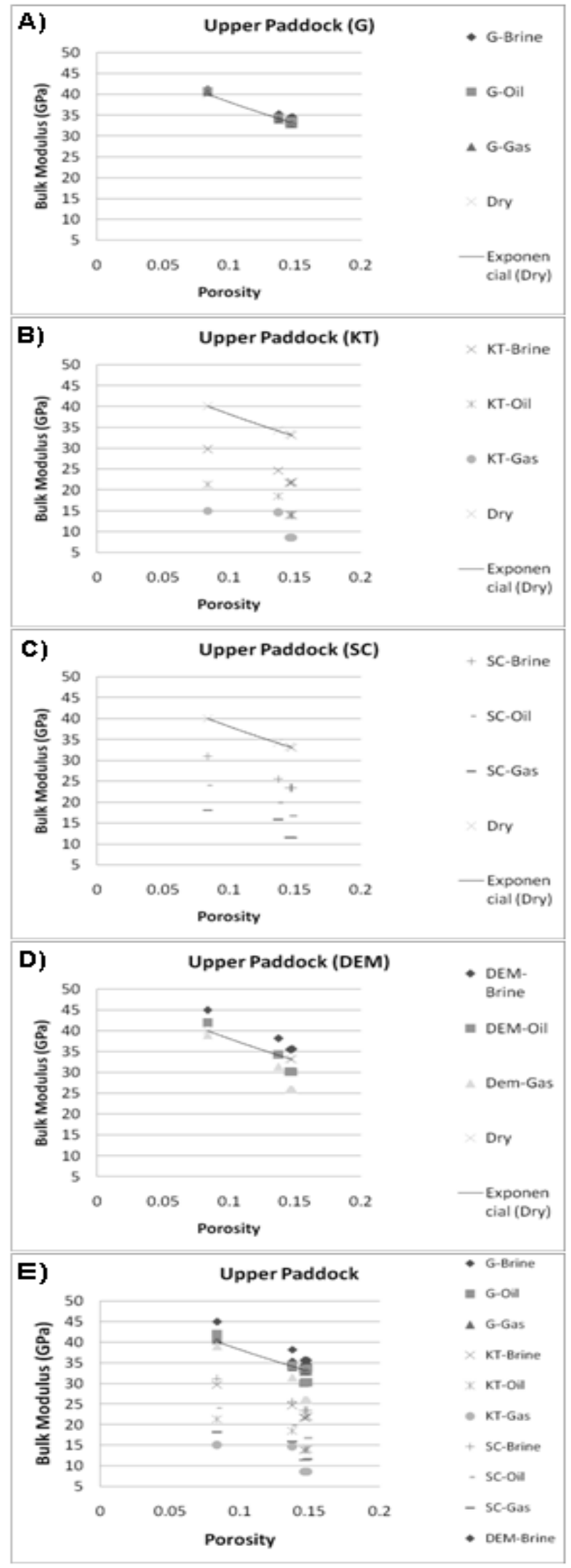

Figure 5 - Analogy between G, KT, SC and DEM models. The full line represents dry conditions data. The KT showed more range fluid saturation sensibility by Upper Paddock limestone. The crossplot (E) shows all models in comparison.

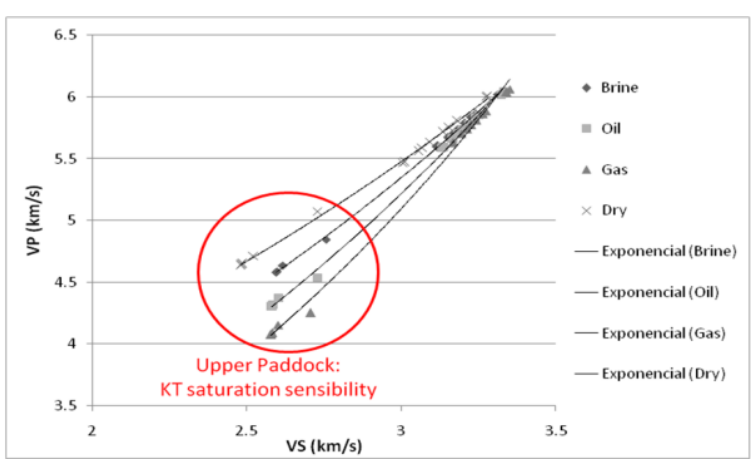

Figure 6 - Seismic velocities for fluid saturation calculated by KT model. In red, Upper Paddock saturation sensibility. Verified non-linear tendency for carbonates second Castagna et al. (1993).

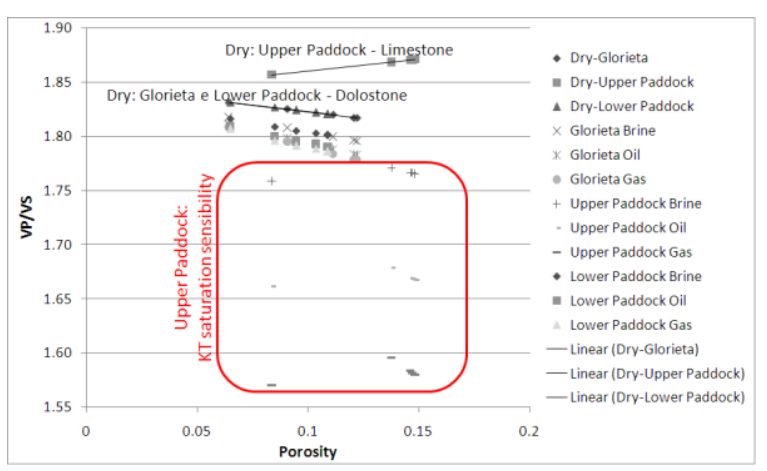

Figure 7 - Calculated for situations of dry rock and different saturations as model KT. Emphasis on the variation of saturation in the formation Paddock higher. It is possible the lithology discrimination (Castagna et al., 1993).

The Fig. 6 shows a non-linear trend for crossplot $P$ and $S$ seismic velocities, typical characteristic in carbonate rocks, suggesting pore geometry heterogeneity, the opposite situation occurs in siliciclastic rocks by homogeneous pore system (Castagna et al., 1993).

Through Fig. 7 is possible to evaluate rock type formations: Upper Paddock limestone, Lower Paddock and Glorieta dolostones, additionally the fluid phase saturations in Upper Paddock. The mineralogical average composition confirms the expected correlation to GlorietaPaddock reservoir: 1.7 - dolomite (Glorieta and Lower Paddock dolostones) and 1.9 - calcite (Upper Paddock limestone). 


\section{Conclusions}

With the implementation of the methodology, it was possible to classify and analyze the pore system in Glorieta-Paddock carbonate reservoir case study. We estimated directly the elastic modulus under saturation or dry conditions. In fact, the greatest potential of Upper Paddock to store fluids is proved by seismic and higher sensitivity results. The pore geometries in the Upper Paddock, interparticle under the microcrack influences, resulted in lower stiffness rock causing an increase in seismic sensibility. Glorieta and Lower Paddock presented interparticle porosity under the spherical geometry influence, reflecting an increase of rigidity rock and reduction of seismic sensibility. Then, a comparative analysis between models was performed. The KT model was chosen by the high saturation sensibility expression. However, the conditions of the available data do not allow a complete representation of the best model for in-situ reservoir conditions. We suggest that the physical modeling of carbonate rocks proposed in this work resulted in an estimate of the elastic modulus, as confirmed to theoretical understanding of the seismic velocities and elastic parameters inversion, important for the characterization of heterogeneous reservoirs.

\section{Acknowledgments}

We thank LENEP-UENF for the supported this work.

\section{References}

ACUNA C. 2000. 4D multicomponent seismic characterization of Glorieta-Paddock carbonate reservoir at Vacuum field, New Mexico. Master of Science (Geophysics) thesis, Colorado School of Mines.

ANSELMETTI FS \& EBERLI GP. 1999. The velocity deviation log: A tool to predict pore type and permeability trends in carbonate drill holes from sonic and porosity or density logs. AAPG Bulletin, 83: 450-466.

BERRYMAN JG. 1980. Long-wavelength propagation in composite elastic media I. Spherical inclusions: J. Acoust. Soc. Am., 68, 1809-1819.

BERRYMAN JG. 1992. Single-scattering approximations for coefficients in Biot's equations of poroelasticity: Journal of the Acoustical Society of America, 91, no. 2, 551-571.

BERRYMAN JG. 1995. Mixture theories for rock properties. In Rock Physics and Phase Relations: a Handbook of Physical Constants, ed. T.J. Ahrens. Washington, DC: American Geophysical Union, 205-228.

CASTAGNA JP \& BACKUS MM. 1993. Offset dependent reflectivity: Theory and practice of AVO analysis: Soc. Expl. Geophysicists, Series 8, 3- 77.

DUNHAM RJ. 1962. Classification of carbonate rocks according to depositional texture. In HAM WE. Classification of carbonate rocks: AAPG Memoir, 108121.
FOLK RL. 1959. Practical petrographic classification of limestones. AAPG Bulletin, 43: 1-38.

GASSMANN F. 1951. Uber die elastizitat poroser medien: Verteljahrss-christ der Naturforschenden Gesellschaft in Zurich, 96: 1-23.

GRAMMER GM, HARRIS PM \& EBERLI GP. 2004. Integration of Outcrop and Modern Analogs in Reservoir Modeling. AAPG Memoir, 80: 191-214.

KUMAR M \& HAN D. 2005. Pore shape effect on elastic properties of carbonate rocks. SEG Technical Program Expanded Abstracts, Society of Exploration Geophysicists, Houston Annual Meeting 2005: 14771481.

KUSTER GT \& TOKSÖZ MN. 1974. Velocity and attenuation of seismic waves in two-phase media, part I theorical formulations. Geophysics, 39: 587-606.

MAVKO G, MUKERJI T \& DVORKIN J. 1998. The Rock Physics Handbook: Tools for Seismic Analysis in Porous Media. Cambridge University Press.

MISAGHI A., NEGAHBAN S., LANDRO M. \& JAVAHERIAN A. 2010. A comparison of rock physics models for fluid substitution in carbonate rocks: Exploration Geophysics, 41, 146-154.

MOORE CH. 1989. Carbonate Diagenesis and Porosity. 1 Ed. New York, Elsevier.

NORRIS AN. 1985. A differential scheme for the effective moduli of composites: Mech. Mater., 4, 1-16.

O'CONNELL RJ. \& BUDIANSKY B. 1974. Seismic velocities in dry and saturated cracked solids: Journal of Geophysical Research, 79, 5412-5426.

RUIZ F. \& DVORKIN J. 2010. Predicting elasticity in nonclastic rocks with a differential effective medium model: Geophysics, 75, 41-53.

WANG HY \& SUN SZ. 2010. A full-frequency band Kuster-Toksöz model and its application in velocity dispersion analysis. Society of Exploration Geophysicists, Technical Program Expanded Abstracts, Denver 2010 Annual Meeting: 2522-2526.

WU TT. 1966. The effect of inclusion shape on the elastic moduli of a two-phase material: Int. J. Solids Structures, 2, 1-8.

XU S. \& WHITE RE. 1995. A new velocity model for claysand mixtures: Geophysical Prospecting, 43, no. 1, 91118.

XU S \& PAYNE MA. 2009. Modeling elastic properties in carbonate rocks. Special section: Rock Physics. The Leading Edge, 28, 1: 66-74.

ZIMMERMAN RW. 1984. The elastic moduli of a solid with spherical pores: new self-consistent method. Int. J. Rock Mech., Mining Sci. Geomech. Abstracts, 21, 339343. 